\title{
SARS-CoV-2 Detection: Fast and Cost-Effective Sample Processing Prior to RT-PCR
}

\author{
Carme Salvador-Garcia ${ }^{1, ~ *, ~ M a r i a ~ D o l o r e s ~ O c e t e-M o c h o n ~}{ }^{1,2}$, Rafael Medina-Gonzalez, \\ Begona Fuster-Escriva ${ }^{1}$, Sonia Cortes-Badenes ${ }^{1}$, Maria Carmen Breso-Vila ${ }^{1}$, \\ Maria Jose Lahiguera-Abalos ${ }^{1}$, Concepcion Gimeno-Cardona ${ }^{1,3}$ \\ ${ }^{1}$ Department of Microbiology, Consorcio General University Hospital of Valencia, Valencia, Spain \\ ${ }^{2}$ Department of Microbiology, School of Medicine, Universidad Catolica San Vicente Martir, Valencia, Spain \\ ${ }^{3}$ Department of Microbiology, School of Medicine, University of Valencia, Valencia, Spain
}

\section{Email address:}

carme.salvador1@um.es (C. Salvador-Garcia), ocete_mar@gva.es (M. D. Ocete-Mochon), medina_rafgon@gva.es (R. Medina-Gonzalez), begonafuster@gmail.com (B. Fuster-Escriva), cortes_sonbad@gva.es (S. Cortes-Badenes),

bresovilamaricarmen@gmail.com (M. C. Breso-Vila), mjlahiguera@hotmail.com (M. J. Lahiguera-Abalos),

concepcion.gimeno@uv.es (C. Gimeno-Cardona)

${ }^{*}$ Corresponding author

\section{To cite this article:}

Carme Salvador-Garcia, Maria Dolores Ocete-Mochon, Rafael Medina-Gonzalez, Begona Fuster-Escriva, Sonia Cortes-Badenes, Maria Carmen Breso-Vila, Maria Jose Lahiguera-Abalos, Concepcion Gimeno-Cardona. SARS-CoV-2 Detection: Fast and Cost-Effective Sample Processing Prior to RT-PCR. International Journal of Biomedical Engineering and Clinical Science. Vol. 7, No. 2, 2021 , pp. 30-34. doi: $10.11648 /$ j.ijbecs.20210702.13

Received: April 24, 2021; Accepted: May 12, 2021; Published: June 4, 2021

\begin{abstract}
The pandemic COVID-19 needs a rapid microbiological diagnostic from Clinical Microbiology Units. Due to the fact that it is done by using a reverse transcription polymerase chain reaction (rRT-PCR) previous RNA extraction and automated equipment and reagents for RNA extraction represent an economic increase to the diagnosis, we describe an easy, cost-effective and fast alternative extraction-free SARS-CoV-2. Samples were treated with proteinase $\mathrm{K}$ for 10 minutes at $55^{\circ} \mathrm{C}$ Then, there is a heat-process for 5 minutes at $98^{\circ} \mathrm{C}$ and finally, 3 minutes at $-20^{\circ} \mathrm{C}$ before a commercial-commonly-used rRTPCR procedure. The RNA automated-extraction was also performed with QIAsymphony RNA Kit (Qiagen) equipment. A total of 220 nasopharyngeal and oropharyngeal swabs were analyzed. 113 samples were tested positive whereas 106 samples were tested negative with RNA automated-extraction and extraction-free method, for an agreement of $99 \%$. A total of one discordant sample was noted in which no amplified result (gene ORF1ab and N) were observed by RNA automated-extraction and gene ORF1ab (Ct 39) and gene N (Ct 37) by extraction-free. Thus, results were comparable with automated-extraction. This method is not only clinically acceptable but also confers an easy, fast, and cost-effective alternative to automatedextraction. Therefore, microbiological laboratories, with low economics resources and/or without automated-extraction equipment, could incorporate it.
\end{abstract}

Keywords: SARS-CoV-2, COVID-19, Molecular Diagnosis, Cost-effective

\section{Introduction}

On January 2020, a new coronavirus -SARS-CoV-2- was detected, triggering the disease called COVID-19 $[1,2]$. SARS-CoV-2 has spread rapidly worldwide and it is now a serious international public health problem and quite alarming, a challenge to society. On the one hand, some patients with severe pathology need admission to Intensive
Care Units; on the other, population screening is essential to control transmission. Consequently, the high capacity and different ways of transmission, makes the microbiological diagnosis crucial for assistance and public health management [3]. Microbiological diagnosis is made by reverse transcription and subsequent real-time PCR (rRTPCR) in nasopharyngeal and/or oropharyngeal swabs after RNA extraction. Given the pandemic situation we are living 
in and the need to perform molecular diagnostics on a significant number of people, the demand for automated RNA extraction reagents is increasing incessantly. As a result, there have been a shortage or stock-outs even though manufacturers are working strenuously to meet the needs [4]. Moreover, automated equipment and reagents for RNA extraction represent an economic increase to the diagnosis. At the time of writing, several thousand new confirmed COVID-19 cases have been reported worldwide. To cope with the surging demand for timely diagnosis of COVID-19 cases, many SARS-CoV-2 molecular assays have become commercially available with extraction included in the same process, such as the Cepheid Xpert Xpress SARS-CoV-2 (Cepheid, CA, USA) or the Roche cobas SARS-CoV-2 (Roche Molecular Systems, NJ, USA). Unfortunately, however, not all laboratories can afford this cost. We describe a simple, cheap and fast workflow as an alternative to automated extraction (AE) for the detection of SARS-CoV-2 nucleic acids (NA).

\section{Methods}

The Microbiology Department of the Consorcio Hospital General Universitario de Valencia (Spain) was one of the three laboratories designated on February 2020 for the microbiological diagnosis of COVID-19 in the Valencian Community. On $27^{\text {th }}$ February 2020, we diagnosed microbiologically the first case of COVID-19 in the province of Valencia and the second case in the Valencian Community. We performed the detection of SARS-CoV-2 from different hospitals. Due to this variability of origins and the high quantity of samples processed daily, we use different viral transport medium, AE equipment and specific rRT-PCR reagents depending on stocks market and the requirements and as well as urgency of the results.

The extraction and purification of NA is the gold standard for molecular diagnostics [5, 6]. However, as many suppliers announced a potential shortage soon after the declaration of the pandemic, we researched whether rRT-PCR could be performed for the detection of SARS-CoV-2 with minimal pre-treatment of samples.

This study was performed with nasopharyngeal (NP) or oropharyngeal (OP) swabs collected with UTM Viral Transport (Copan) or with $3 \mathrm{ml}$ of saline solution (SS). These samples were either positive or negative for SARS-CoV-2 following the usual laboratory protocol. They were frozen at $-80^{\circ} \mathrm{C}$ for storage and later recovered for this study. After defrosting, analysis was again performed using one of the usual laboratory methods (Method 1) and an alternative method was performed simultaneously (Method 2). Method 1 (M1): AE was performed with the QIAsymphony RNA Kit (Qiagen) according to the manufacturer's instructions, obtaining a final RNA extraction product volume of $100 \mathrm{ul}$. Method 2 (M2): $300 \mathrm{ul}$ of sample (UTM or SS) were pipetted into an eppendorf. The sample was previously vigorously vortexed. Proteinase K (TermoFischer Scientific) was directly added at a final concentration of $100 \mathrm{ug} / \mathrm{ml}$ and incubated for 10 minutes at $55^{\circ} \mathrm{C}$. After that, the temperature was set at $98^{\circ} \mathrm{C}$. Then, incubated for 5 minutes more and quickly moved to $-20^{\circ} \mathrm{C}$ for $2-3$ minutes. rRT-PCR was performed for the detection of the ORF1ab and $\mathrm{N}$ genes by Viasure SARS-CoV-2 (Certest Biotec), according to the manufacturer's instructions.

IBM SPSS Statistics version 19 (IMB, Chicago, USA) was used for statistical analysis. The ratio test was performed to evaluate significant qualitative differences (positive or negative results) between $\mathrm{M} 1$ and $\mathrm{M} 2$. On the other hand, the test of averages was performed to analyze differences between the Cts (cycle threshold) obtained depending on the extraction method used. Differences with values of $p<=0.05$ were considered statistically significant.

\section{Results}

We initially analyzed 30 samples. Since our research was satisfactory for this low series, we requested approval from the ethics committee. This study was conducted after receiving approval from the Ethics Committee of Fundació Investigació Hospital General Universitari de Valencia (Comité Ético de Investigación con medicamentos, Reference Number 139/2020).

All the clinical samples used in this study have been anonymized and an exemption from the informed consent of the patient has been requested, since the study carried out is the same for which they were obtained.

A total of 220 clinical frozen NP/NO samples (114 positive and 106 negative samples) were performed in parallel on both, M1 and M2, to allow for a head-to-head comparative analysis. Of the 220 samples, 48 (27 positive and 21 negative) were collected in SS and 172 (87 positive and 85 negative) in UTM. Table 1 shows initial cycle threshold $(\mathrm{Ct})$ positive samples before freezing.

Table 1. Initial Cts range ORFabl and $N$ gene before freezing.

\begin{tabular}{llll}
\hline Ct $_{\text {ORFab1 }}$ & Number of samples & $\mathbf{C t}_{\mathbf{N}}$ & Number of samples \\
\hline$<20$ & 15 & $<20$ & 13 \\
$20-29.9$ & 58 & $20-29.9$ & 59 \\
$30-34.9$ & 35 & $30-34.9$ & 35 \\
$>=35$ & 6 & $>=35$ & 7 \\
\hline
\end{tabular}

Following re-testing of 220 swabs, there were 113 tested positive and 106 tested negative with both methods, for an agreement of $99 \%$. A total of 1 discordant sample was noted in which no amplified result (gene ORF1ab and N) were observed by M1 and gene ORF1ab (Ct 39) and gene N (Ct 37) by $\mathrm{M} 2$.

The median $\mathrm{Ct}$ (Figure 1A) values for the gene ORF1ab by the M1 and M2 assays were 28.18 (interquartile range (IQR) 24.52-32.06) and 30.05 (IQR 25.57-34.86), respectively. The gene ORF1ab result of five samples with M1 was no amplified. However, Ct 34.38-40.56 were detected with M2. For M2, we observed no amplified gene ORF1ab result in 4 samples. These samples had Cts from 32 to 38 . The median $\mathrm{Ct}$ values for the $\mathrm{N}$ gene target were 28.58 (IQR 25.02-33.36) and 28.91 (IQR 25.5-33.22) (Figure 1B), respectively. 
Discordant no amplified results were not observed in $\mathrm{N}$ gene target.

No significant differences in the interpretation were observed in any of the samples comparing M1 and M2. Nevertheless, the ORFab1 gene was not detected in 5 samples performed with the M1 and in 4 processed with M2.
In these samples, following the manufacturer's instructions, the result should be confirmed with another method but in no case should a false negative result have occurred. Although, in these samples high Cts were showed (Cts 34.38-40.56, M2) and (Cts 32-38, M1) (see above).

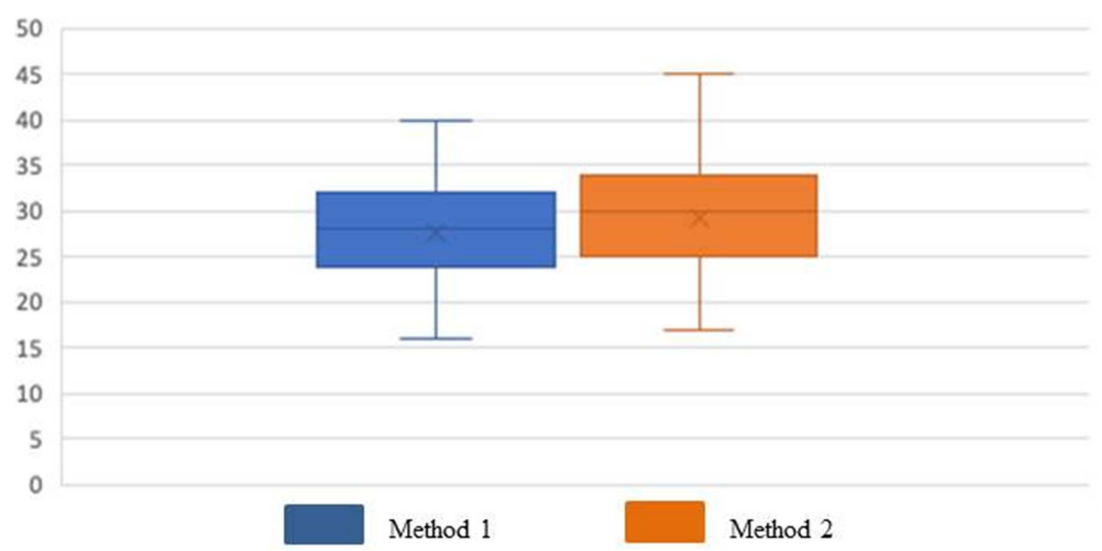

(A)

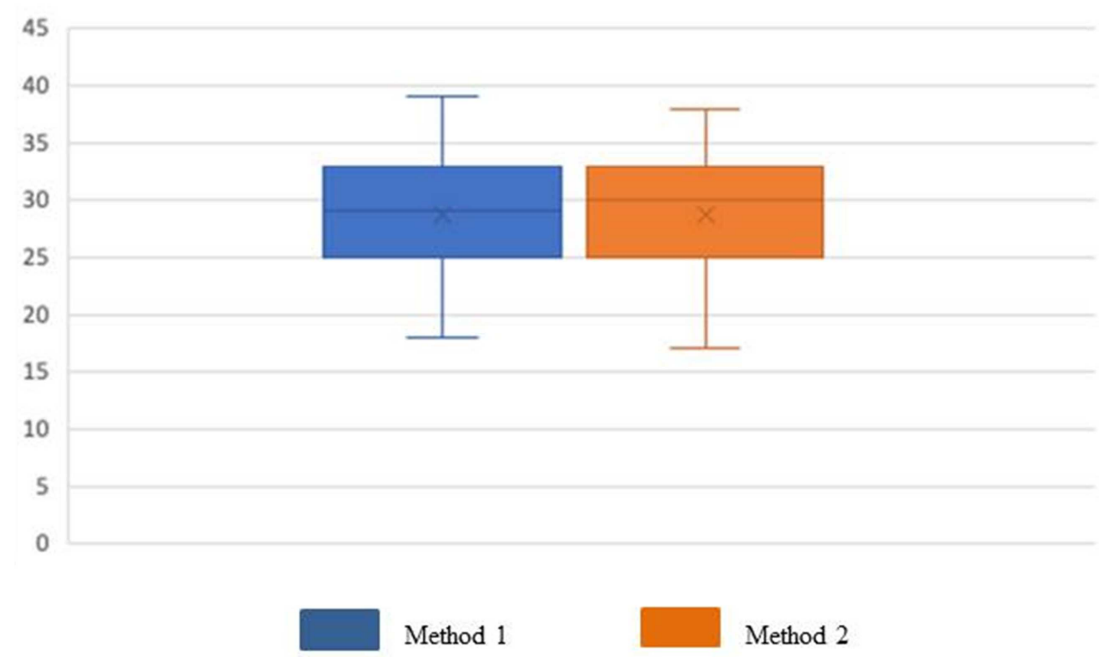

(B)

Figure 1. (A) Dot and box plots of the ORFab1 gene cycle threshold (Ct) values obtained with the Method 1 and Method 2 extractions for all positive samples. (B) Dot and box plots of the $N$ gene $C t$ values obtained with the Method 1 and Method 2 extractions for all positive samples.

Regarding the Cts, the median difference between the Cts of the samples extracted with M1 and M2 was $1.16(0.08$ 8.74) and $0.17(0.02-5.98)$ for ORFab1 and $\mathrm{N}$ gene respectively. This difference was not statistically significant for $\mathrm{N}$ gene. Furthermore, it was observed that $40.8 \%(42 / 103)$ and $63.7 \%(72 / 113) \mathrm{Cts}$ were numerically lower with M2 than with $\mathrm{M} 1$ for ORFab1 and $\mathrm{N}$ gene respectively.

\section{Discussion}

In this study, we detected 113 positive and 106 negative specimens with minimal impact on $\mathrm{Ct}$ values as compared to AE. We observed only a discordant result, which was negative by $\mathrm{AE}$ and positive (ORFab1 Ct 39 and $\mathrm{N} \mathrm{Ct37)} \mathrm{by}$ PK-thermal-method. We successfully optimized a direct rRTPCR method to detect SARS-CoV-2 RNA in NP/NO swabs.
Our RNA extraction process was evaluated on a greater number of positive specimens with a wider range of $\mathrm{Ct}$ values.

Interestingly, all low viral load samples were detected with the $\mathrm{N}$ gene using this assay. One possible explanation is a higher sensitivity of the $\mathrm{N}$ gene primers. While the $\mathrm{N}$ gene sequence is present in all subgenomic mRNAs, ORFab1 is less represented [7]. Studies report that infectivity from these patients is limited [8-13], and we arrived to conclude that missed positive samples using our method with ORFab1 gene $\mathrm{Ct}$ values above 34 have little clinical relevance.

Following the results previously published by Fomsgaard [14], we performed the heat shock at $98^{\circ} \mathrm{C}$ for 5 minutes adding a pre-treatment with proteinase $\mathrm{K}$ to show if it improved sensitivity. It seems that the use of proteinase $\mathrm{K}$ not only improves the results, but also the amount of time and 
treatment of the additional sample is minimal. Malman et al. [15] published good results with proteinase $\mathrm{K}$, however the number of samples analyzed were low in order to conclude.

For the study we selected 48 samples collected in SS, the stocks of SS are safer and cost reduction is obvious, so that the study with this type of preservation allows to have an alternative method of extraction validated with a means of transport/preservation available in all centers.

This method is not only clinically acceptable but also confers an easy, fast, and cost-effective alternative to AE. Additionally, this method reduces the cost, and then ease microbiological laboratories, with low economics resources and/or without $\mathrm{AE}$ equipment, incorporate it.

\section{Conclusion}

We have demonstrated some improvements in COVID-19 viral testing workflow using 220 samples employing PK-heat extraction-free workflow. A PK-heat processing method is effective with an agreement of 99\% (only 1 discordant sample result) when compared to a RNA automatedextraction method and, in addition, it shows a strong correlation between the two methods based on the $\mathrm{Ct}$ values. We recommend this method is explored further by other medical laboratories using alternative PCR reagents to improve the resilience and capacity of microbiology laboratories. This methodology simplifies the process for COVID-19 testing and will enable increased capacity in diagnostic laboratories, reporting positive cases in less than 1.5 hours, which could play an important role in the diagnostic and surveillance of COVID-19. Furthermore, it has a clear benefit of easy adaptation and cost saving to clinical laboratories because no need of an extraction equipment.

\section{Author Contributions}

All authors made ample contributions this study. For the submission of this study all authors also approved the final version.

\section{Conflicts of Interest}

The authors declare that they have no competing interests.

\section{Research Funding}

This research did not receive any specific grant from funding agencies in the public, commercial, or not-for-profit sectors.

\section{Ethical Approval}

Ethics approval was granted by the Consorcio Hospital General Universitario de Valencia. Comité Ético de Investigación con Medicamentos. Reference Number 139/2020.

\section{Acknowledgements}

We thank M. T. Sanz García and J. A. Gómez Cortés for statistical analysis and linguistic considerations respectively and the staff at the Consorcio Hospital General Universitario de Valencia involved in COVID-19 diagnostic testing.

\section{References}

[1] WHO. Coronavirus disease (COVID-19) pandemic [Internet]. www.who.int: WHO; 2020 [updated 202020 April]. Available from: https://www.who.int/emergencies/diseases/novelcoronavirus-2019.

[2] Zhou P, Yang XL, Wang XG, Hu B, Zhang L, Zhang W, et al. A pneumonia outbreak associated with a new coronavirus of probable bat origin. Nature. 2020, 579 (7798): 270-3. doi: 10.1038/s41586-020-2012-7.

[3] Wong JE, Leo YS, Tan CC. COVID-19 in Singapore. Current Experience: Critical Global Issues That Require Attention and Action. JAMA. 2020, 323 (13): 1243-4. doi: 10.1001/jama.2020.2467.

[4] Akst J. RNA Extraction Kits for COVID-19 Tests Are in Short Supply in US [Internet]. www.thescientist.com: The Scientist.; 2020 [updated 202011 March]. Available from: https://www.the-scientist.com/news-opinion/rna-extractionkits-for-covid-19-tests-are-in-shortsupply-in-us-67250.

[5] Chu DKW, Pan Y, Cheng SMS, Hui KPY, Krishnan P, Liu Y, et al. Molecular Diagnosis of a Novel Coronavirus (2019nCoV) Causing an Outbreak of Pneumonia. Clin Chem.2020. 66 (4): 549-55. doi: 10.1093/clinchem/hvaa029.

[6] Corman VM, Landt O, Kaiser M, Molenkamp R, Meijer A, Chu DKW, et al. Detection of 2019 novel coronavirus (2019$\mathrm{nCoV}$ ) by real-time RT-PCR. Euro Surveill. 2020, 25 (3). doi: 10.2807/1560-7917.ES.2020.25.3.2000045.

[7] Kim D, Lee JY, Yang JS, Kim JW, Kim VN, Chang H. The architecture of SARS-CoV-2 transcriptome. Cell. 2020, 181 (4): 914-2110.

[8] Bullard J, Dust K, Funk D, Strong JE, Alexander D, Garnett L, et al. Predicting infectious SARS-CoV-2 from diagnostic samples. Clin Infect Dis. 2020. https://doi.org/10.1093/cid/ciaa638.

[9] La Scola B, Le Bideau M, Andreani J, Hoang VT, Grimaldier C, Colson P, et al. Viral RNA load as determined by cell culture as a management tool for discharge of SARS-CoV-2 patients from infectious disease wards. Eur J Clin Microbiol Infect Dis. 2020, 39 (6): 1059-61.

[10] Zheng S, Fan J, Yu F, Feng B, Lou B, Zou Q, et al. Viral load dynamics and disease severity in patients infected with SARSCoV-2 in Zhejiang province, China, January-March 2020: retrospective cohort study. BMJ. 2020, 369: m1443.

[11] Huang CG, Lee KM, Hsiao MJ, Yang SL, Huang PN, Gong $\mathrm{YN}$, et al. Culturebased virus isolation to evaluate potential infectivity of clinical specimens tested for COVID-19. J Clin Microbiol. 2020. https://doi.org/10.1128/ JCM.01068-20.

[12] Folgueira MD, Luczkowiak J, Lasala F, Perez-Rivilla A, Delgado R. Persistent SARS-CoV-2 replication in severe COVID-19. medRxiv. 2020. https://doi. org/10.1101/2020.06.10.20127837. 
[13] Zou L, Ruan F, Huang M, Liang L, Huang H, Hong Z, et al. SARS-CoV-2 viral load in upper respiratory specimens of infected patients. N Engl J Med. 2020, 382 (12): 1177-9.

[14] Fomsgaard AS and Rosenstierne MW. An alternative workflow for molecular detection of SARS-CoV-2 - escape from the NA extraction kit-shortage, Copenhagen, Denmark. March, 2020. https://doi.org/10.1101/2020.03.27.20044495.
[15] Mallmann L, Schallenberger K, Demolliner M, Antunes Eisen AK, Saraiva Hermann B, Heldt FH, et al. Pre-treatment of the clinical sample with Proteinase $\mathrm{K}$ allows detection of SARSCoV-2 in the absence of RNA extraction. 2020. https://doi.org/10.1101/2020.05.07.083139. 